\title{
Relações internacionais e mídia
}

\author{
Raquel Boing Marinucci'
}

\section{Resumo}

O ensaio aponta e discute possíveis razões para a ausência de estudos abordando o papel da mídia nas Relações Internacionais. A autora mostra que a teoria internacionalista, em grande parte, vê na mídia uma coadjuvante, como instrumento de persuasão. O relativo silêncio da academia é quebrado pela corrente crítica, especialmente através do modelo de propaganda de Noam Chomsky. Ao final, são sugeridas leituras para os interessados em conhecer o enfoque.

Palavras-chave: Mídia. Relações internacionais. Teoria.

\section{Introdução}

É inimaginável conceber o cotidiano sem a interferência de algum instrumento de mídia. Ela permeia e modifica as relações entre indivíduos, altera a percepção do tempo, modifica a nossa relação com o espaço, seja através do telefone fixo ou celular, televisão, jornal, cinema, rádio, internet para se falar das mais 'convencionais'.

Embora pareça impossível negar a centralidade dos meios de comunicação no mundo contemporâneo, a academia de Relações Internacionais (RI), bem como seus manuais, deixa a temática relegada à 'marginalidade'. Quais as razões para essa condição? Os estudos, de fato, não existem? Existem, mas não se encontram estruturados a partir das categorias analíticas do campo e, por isso, são ignorados? Estão atrelados a correntes que não são centrais e acabam ocupando pouco espaço? É uma temática nova que ainda concorre com outros assuntos também ainda pouco explorados? O presente ensaio não pretende esgotar esses questionamentos, tão somente apontá-los, indicando alguns caminhos e possíveis respostas, procurando demonstrar a necessidade de se abrir mais espaço para estudos da mídia no campo.

${ }^{1}$ Mestre em Ciência Política pela Universidade de Brasília. Professora do UniCEUB (Brasília - DF) desde 2001. 


\section{Qual o espaço da mídia nos estudos de RI?}

No extenso e pertinente levantamento bibliográfico elaborado pelo professor Paulo Roberto de Almeida (2006), praticamente não há referência a estudos sobre os meios de comunicação, tecnologias de informação, opinião pública ou assuntos correlatos que possam ser enquadrados de modo geral como 'mídia'. A obra fornece ao leitor mais de sessenta páginas com indicações bibliográficas, formando um 'guia da produção em relações internacionais do Brasil e bibliografia geral. Pode-se imaginar que, como o foco do levantamento seja o diálogo entre a diplomacia e a academia, não seria de se esperar destaque para a temática, ainda mais ao se considerar o grande volume da produção brasileira em assuntos como história, política externa, defesa e o próprio papel do Ministério das Relações Exteriores. No entanto, há vários assuntos que poderiam ser considerados novos ou de interesse secundário - para os que formam o eixo central da disciplina - que estão presentes no levantamento, tais como direitos humanos, migrações, comércio exterior e questões ambientais ${ }^{2}$.

Há, na verdade, ausência não somente de estudos que abordem a temática das comunicações, mas, sobretudo, de textos importantes que servem de base para esses estudos no Brasil e em outros centros. Não há qualquer menção a Marx, Gramsci ou a contemporâneos como Robert Cox ou Noam Chomsky, identificados como precursores ou integrantes da corrente 'crítica'. Cabe mencionar que são feitas referências a Immanuel Wallerstein e a Octavio Ianni que também produzem interpretações críticas, mas provavelmente consideradas mais 'científicas' para os parâmetros da academia internacionalista. $\mathrm{O}$ fato de que tais assuntos ou autores críticos não estejam listados no manual de Almeida, obviamente não diminui a importância do levantamento bibliográfico, obra indispensável a qualquer estudante ou professor da área.

$\mathrm{Na}$ verdade, o que se percebe é que o manual reforça as características principais dos estudos de RI ainda muito preocupados com a delimitação do campo e a possível interferência de outras áreas. Durante anos, a disciplina se concentrou em debater questões metodológicas, especialmente entre behavioristas

\footnotetext{
${ }^{2}$ Ausência ainda maior que a da mídia parece ser o estudo sobre gênero e a teoria feminista.
} 
e tradicionalistas ${ }^{3}$, avançando pouco do que seria esperado na aplicação dos seus instrumentos analíticos. $\mathrm{O}$ ainda forte positivismo metodológico talvez seja uma explicação razoável para entender a dificuldade em se trabalhar com temas 'pouco convencionais' como o papel da mídia no cotidiano dos países e na política internacional.

Em termos práticos, as relações internacionais, muito por influência da academia norte-americana, acabaram colocando o hard power, as questões de segurança, armamento e defesa, no centro das atenções. Por sua vez, o assim chamado soft power, termo usado para se referir de modo genérico às disputas em torno das ideias, a capacidade de persuasão, é reconhecido, mas apenas como auxiliar e jamais como protagonista das teorias de relações internacionais ${ }^{4}$. Nesse contexto, mesmo que intuitivamente qualquer leigo perceba a interferência da mídia no seu cotidiano, para tê-la como objeto das relações internacionais, será preciso ultrapassar as barreiras que a própria disciplina construiu ao longo da sua trajetória, denominando-se ontologicamente racionalista e epistemologicamente positivista (SMITH, 2002, p. 67-85).

\section{A mídia como soft power}

Um dos primeiros manuais específicos de RI publicados no Brasil foi o de Wendzel (1985), original de 1977. O autor pode provavelmente ainda hoje expressar em grande parte o pensamento das relações internacionais no que ser refere ao papel da mídia como soft power. O objetivo principal da obra é delimitar o modo como a política externa é formulada: quais os atores, quais os condicionantes, quais os instrumentos utilizados. Os meios de comunicação aparecem em dois momentos.

No primeiro, o autor aborda os instrumentos de implementação da política, trabalhando o papel da comunicação. Para Wendzel (1985, p. 205), "no século XX, a revolução na comunicação exerceu grande influência na conduta das relações

\footnotetext{
${ }^{3}$ Para uma síntese dos debates ver, por exemplo: VIOTTI, Paul R.; KAUPPI, Mark V. International Relations Theory. 3. ed. Boston: Allyn and Bacon, 1998.

${ }^{4}$ Recentemente, Nye, um dos autores que utiliza a categoria, reavaliou sua importância no pós 11 de setembro. Ver: NYE, Joseph S. The decline of America's soft power: why Washington should worry. Foreign Affairs, [S.1], n. 3, v. 83, p. 16-20, May/June 2004.
} 
internacionais". Na sua concepção, a relevância da comunicação estaria na crescente utilização e preocupação dos governos com seus departamentos de propaganda. Para ele, portanto, a mídia, através de meios variados, serve como 'arma' (expressão usada pelo autor) de propagação das ideias de um país. Embora Wendzel tente mostrar que a propaganda não é necessariamente mentirosa, acaba reforçando a noção de que os meios de comunicação são importantes por permitirem aos atores a manipulação de dados na projeção de sua imagem no exterior, mesclando verdade e mentira. Para ele, "a comunicação é uma peça importante no arsenal do formulador de política" (WENDZEL, 1985, p. 212), reforçando a visão de que a política internacional é essencialmente um jogo de forças, nos moldes do paradigma realista. Ainda no mesmo tópico, o autor reforça que a comunicação não dever ser supervalorizada na formulação da política externa, já que tem seu impacto limitado pelo fato de o grande público não ser, segundo ele, atingido pelas questões internacionais. Ou seja, os meios de comunicação servem para fazer propaganda, permitindo que o líder os use como mecanismos de persuasão, colaboradores do eixo centrado na segurança e na corrida armamentista. Novamente, deve-se compreender a visão do autor no contexto da política bipolar e do predomínio do realismo, com suas categorias analíticas muito ligadas ao pretenso caráter unitário do Estado e à noção de interesse nacional.

Em outra parte do manual, o autor destaca o papel da mídia na relação com a política interna, destacando a construção da 'opinião pública'. Ao final dos anos 70, seria pouco razoável negligenciar o papel da opinião pública no processo decisório, tendo em vista as manifestações no período da Guerra do Vietnã. Ao tratar do assunto, Wendzel (1985, p. 277) aproveita para alfinetar o polo socialista, afirmando que a temática não teria relevância alguma em sistemas como o soviético e o chinês, já que lá a população seria “apenas um instrumento de manobra nas mãos de formuladores de política”. Desse modo, o possível impacto da opinião pública deveria ser considerado apenas nos países democráticos do bloco capitalista. Sua conclusão será a de que o grande público não influencia a formulação da política externa e que, ao contrário, na verdade busca informações com o formulador de políticas para se orientar. Não há qualquer referência ao modo como a opinião é construída, quais os instrumentos utilizados, como a população se relaciona com os conteúdos, quem são os proprietários dos veículos de informação e quais os mecanismos. Além do tomador de decisão, apenas é citado o partido político, pretensamente como base da organização dos interesses dos cidadãos. 
Fica então a sensação de que a mídia não precisa ser estudada no âmbito da formulação da política externa, pois seu papel é bastante pontual e simplório: ou serve como manipulação por parte de governos no cenário internacional, por meio da propaganda; ou serve para legitimar os assuntos internacionais junto à população doméstica, já pouco interessada na política e ainda mais distante da política internacional.

Do início dos anos 80, quando o manual de Wendzel era bastante usado, até hoje, com o que podemos chamar de 'popularização' dos cursos de Relações Internacionais no Brasil, tivemos uma ampliação significativa na edição de manuais e de textos clássicos destinados aos discentes. Em um manual recentemente traduzido para português (JACKSON; SØRENSEN, 2007), que já traz o debate em torno dos novos temas nas relações internacionais, persiste a ausência da temática da mídia, tanto como algo já estudado ou que mereça mais atenção dos pesquisadores. Há, no entanto, a referência a autores como o neogramsciano Robert Cox, que destaca a importância das ideias e das instituições como forças sociais que devem ser levadas em consideração juntamente com as formas de Estado e a ordem mundial. As aplicações da teoria do Estado ampliado de Gramsci, destacando o papel da sociedade civil e de seus aparelhos privados de hegemonia - dentre eles o aparato material da cultura - abrem espaço para os estudos de mídia em relações internacionais.

\section{0 status da mídia na Ciência Política}

As reflexões gramscianas em torno do conceito de hegemonia orientam parte de estudos da teoria política preocupados com o papel dos meios de comunicação, embora o foco esteja no cenário interno. A busca pela delimitação dos cenários internacional e 'doméstico’ nos cursos de Relações Internacionais e Ciência Política acabou distanciando suas reflexões teóricas: enquanto na Ciência Política já há o reconhecimento da produção na área de mídia e política, por exemplo, as Relações Internacionais continuam com o enfoque na política como força, segurança e quando muito, admitindo que a reflexão deveria contemplar o plano interno, passando por análises do processo decisório. Na Ciência Política, abre-se espaço para as reflexões sobre a interferência da mídia especialmente por duas dimensões: uma onde se parte do pressuposto de que a política se caracteriza muito mais pela 
dimensão da deliberação ${ }^{5}$ do que pela força; e outra, pelos efeitos da mídia no processo político ${ }^{6}$, tornando-o menos secreto e mais aberto ao controle do público em geral (pelo menos em uma parte dos eventos, já que a política continua mantendo a legitimidade de áreas restritas à discussão de políticos e burocratas). Portanto, embora a Ciência Política continue trabalhando com o ingrediente da força, há uma linha - mais aberta aos diálogos com os departamentos de comunicação - que procura, por motivos diferentes, explorar as disputas simbólicas ${ }^{7}$.

É justamente essa linha que destaca a necessidade de se abordar de modo mais sistemático a interferência dos meios de comunicação na realidade contemporânea, especialmente nos estudos que buscam compreender os instrumentos democráticos. Nesse sentido, Miguel (2000, p. 51-77) indica um ponto cego na teoria democrática no que se refere à não identificação da importância dos meios de comunicação na formação das preferências eleitorais, por exemplo.

Percebe-se, desse modo, que, embora já exista uma linha de pesquisa que considere os estudos da mídia no âmbito da Ciência Política, não há ainda um consenso sobre seu papel, tampouco o reconhecimento - elemento fundamental na academia - de outras linhas de pesquisa sobre sua relevância para o campo ${ }^{8}$. A 'cegueira' do campo da política interna, no entanto, consegue ser percebida.

Nos estudos da política internacional, a radicalidade tem sido a estratégia para denunciar a indiferença da academia de RI aos meios de comunicação.

\section{0 radicalismo do 'consenso fabricado'}

O autor mais apontado como radical pela academia de RI é, sem dúvida, o norte-americano Noam Chomsky. Embora tenha reconhecimento do campo da

\footnotetext{
${ }^{5}$ Como Hannah Arendt, por exemplo, filósofa que coloca a importância do discurso como momento central da formação da subjetividade.

${ }^{6}$ Como Jürgen Habermas e os estudos sobre as mudanças da esfera pública e a importância do agir comunicativo.

${ }^{7}$ Para um levantamento dos estudos de mídia e política, ver o levantamento feito por Rubim em: RUBIM, Antonio Albino Canelas. Comunicação e política. São Paulo: Hacker, 2000.

${ }^{8}$ Vale mencionar o pioneirismo do professor Venício Artur de Lima, fundador do Núcleo de Estudos sobre Mídia e Política da Universidade de Brasília e grande incentivador da linha de pesquisa no Brasil.
} 
linguística, Chomsky costuma usar seu capital simbólico para atuar politicamente, sendo um dos críticos mais ferrenhos da inserção internacional da política estadunidense.

A principal crítica ao modo como os Estados Unidos se utilizam dos meios de comunicação está na obra em parceria com Edward Herman, Manufacturing consent, de 1988. A obra foi publicada no Brasil apenas em 2003, com o título de Manipulação do público, embora o termo 'consenso fabricado' já fosse bastante difundido no Brasil.

Os autores aplicam o que chamam de 'modelo de propaganda' a vários casos, passando pela cobertura do atentado ao Papa a eleições em países da América Central. O espírito que inspira a análise pode ser descrito já em uma das epígrafes, de autoria de John Milton: "Aqueles que vazaram os olhos do povo, o recriminam por sua cegueira". Para os autores, os meios de comunicação são instrumentos de manipulação, sendo centrais no processo político, especialmente no internacional. O caráter soft que as teorias realista ou liberal atribuem à mídia se fortalece, ganhando centralidade na interpretação chomskyana.

O 'consenso fabricado' aborda o desempenho da mídia dos EUA, a partir da noção de que existem fatores estruturais que funcionam como filtros para a produção da notícia. Não há, no entanto, uma relação mecânica entre o que a mídia aborda e os efeitos produzidos no público. O efeito sobre a população, aliás, não é o eixo da interpretação dos autores, mas sim como a mídia se relaciona com os interesses econômicos e políticos. Eles buscam entender as forças que moldam o que a mídia faz, destacando o caráter corporativo e sua simbiose com a política econômica, especialmente em tempos de globalização e de grandes empreendimentos tecnológicos transnacionais (HERMAN; CHOMSKY, 2003).

Que a mídia é um dos ramos mais concentrados em termos econômicos e que os políticos a utilizam não é segredo para ninguém. Mesmo assim, a análise de Chomsky não consegue o respaldo da academia de RI, sendo considerado panfletário. Dado o 'americanismo' da teoria, como colocado anteriormente, acaba sendo compreensível a resistência em colocá-lo como referência nos manuais. No entanto, apesar de 'ácido', não se pode dizer que Chomsky faça análises infundadas. São parciais, mas o mesmo pode ser dito de análises realistas do contexto da Guerra 
Fria, por exemplo. A insistência da academia na crença da objetividade da ciência faz com que os estudantes da área acabem não tendo a oportunidade de conhecer tal tipo de análise (mesmo que seja para conhecê-la e descartá-la).

\section{Por onde começar?}

Dado o relativo silêncio dos manuais em relação à mídia, por onde um estudante de RI, interessado em conhecer mais sobre a temática, poderia começar suas leituras? Dado o breve espaço deste ensaio, podem ser sugeridos alguns textos básicos, além dos já citados, disponíveis em português.

Um primeiro nome, com respaldo acadêmico e citado em manuais como o de Jackson e Sørensen, seria Manuel Castells (1993), com sua trilogia, especialmente o primeiro volume destinado à Sociedade em rede. Nele são discutidos, por exemplo, elementos como as transformações culturais e políticas causadas pelas tecnologias de informação, a globalização econômica e as consequências produtivas na diversificação dos fluxos. Mais do que se aprofundar nas temáticas, o autor faz um panorama geral sobre as mudanças do final do milênio e a formação do que chama de 'sociedade em rede', ligada política, econômica e culturalmente pelas tecnologias de informação.

Em segundo lugar, para um histórico do papel da mídia na política internacional desde a era do telégrafo ao início dos anos 90, Armand Matterlart (1994) com Comunicação-Mundo. O autor francês narra o papel dos meios de comunicação, estabelecendo um tripé entre guerra, progresso e cultura para explicar a importância da mídia política internacional. É uma leitura essencial para entender a mídia para além da categoria de soft power, como mera coadjuvante.

Para uma leitura mais diversificada sobre os diversos aspectos que envolvem a mídia no cenário contemporâneo - questões culturais, papel da internet, propriedade dos meios e cidadania - há uma coletânea organizada por Moraes (2004) que conta com textos de vários autores importantes das Ciências Sociais como o próprio Castells, Edgar Morin e David Harvey. São textos diversos que permitem uma abertura de caminhos plurais para a compreensão da mídia na atualidade. 
Por fim, uma temática específica de interesse do internacionalista, o terrorismo, analisado sob o foco da mídia, a partir do texto Mídia e terror. No livro, Wainberg (2005) analisa o papel da mídia na prática terrorista, trabalhando várias categorias das RI como a teoria dos jogos e o choque das civilizações.

A interface mídia-relações internacionais apresenta muitas possibilidades de estudos para o internacionalista, desde enfoques mais econômicos aos efeitos culturais e políticos. As sugestões de leituras e as provocações aqui apresentadas pretenderam sensibilizar o estudante para a importância da temática dentro do campo. Obviamente, permanece o problema metodológico de como abordá-la para atender aos critérios acadêmicos ainda tão conservadores nas RI. Talvez os que se aventurarem por esse caminho perceberão como Gramsci, que a estratégia adequada neste caso seja travar uma 'guerra de posição', assumindo seu caráter contra-hegemônico dentro do campo, esperando que sua relevância se mostre ao longo do processo.

\section{Relaciones Internacionales y los médios de comunicación}

\section{Resumen}

El texto identifica y discute las posibles razones de la falta de estudios sobre el papel de los medios de comunicación en las relaciones internacionales. El autor muestra que la teoría internacionalista, en gran parte, ve en los medios de comunicación un adyuvante, como instrumento de persuasión. El relativo silencio de la academia se verá interrumpida por la crítica, especialmente a través del modelo de propaganda de Noam Chomsky. Al final, se sugieren lecturas para aquellos interesados en conocer el enfoque.

Palabras-clave: Médios de comunicación. Relaciones internacionales. Teoría.

\section{Referências}

ALMEIDA, Paulo Roberto. O estudo das relações internacionais do Brasil: um diálogo entre a diplomacia e a academia. Brasília: LGE, 2006.

CASTELLS, Manuel. A era da informação: economia, sociedade e cultura. Tradução de Roneide Venancio Majer. São Paulo: Paz e Terra, 1993. 3 v. 
HERMAN, Edward S.; CHOMSKY, Noam. A manipulação do público. São Paulo: Futura, 2003.

JACKSON, Robert; SØRENSEN, George. Introdução às relações internacionais. Tradução de Bárbara Duarte. Rio de Janeiro: J. Zahar, 2007.

MATTELART, Armand. Comunicação-mundo: história das idéias e das estratégias. Tradução de Guilherme João de Freitas Teixeira. Petrópolis: Vozes, 1994.

MIGUEL, Luis F. Um ponto cego nas teorias da democracia: os meios de comunicação. BIB, Rio de Janeiro, n. 49, p. 51-77, Jan./Jun. 2000.

MORAES, Dênis (Org.). Por uma outra comunicação: mídia, mundialização cultural e poder. 2. ed. Rio de Janeiro: Record, 2004.

NYE, Joseph S. The decline of America's soft power: why Washington should worry. Foreign Affairs, [S.1], n. 3, v. 83, p. 16-20, May/June 2004.

RUBIM, Antonio Albino Canelas. Comunicação e política. São Paulo: Hacker, 2000.

SMITH, Steve. The United States and the discipline of international relations: hegemonic country, hegemonic discipline". International Studies Review, [S.1.], v. 4, n. 2, p. 67-85, summer 2002.

VIOTTI, Paul R.; KAUPPI, Mark V. International relations theory. 3. ed. Boston: Allyn and Bacon, 1998.

WAINBERG, Jacques A. Mídia e terror: comunicação e violência política. São Paulo: Paulus, 2005.

WENDZEL, Robert L. Relações Internacionais: o enfoque do formulador de políticas. Tradução de João de Oliveira Dantas, Julio Galvez e Pantaleão Soares de Barros. Brasília: Universidade de Brasília, 1985. 